\title{
Validation of a Low Cost Horse Saddle Stabilometric Platform to Analyze the Rider's Balance
}

\author{
Dominique Prin-Conti ${ }^{1}$, William Bertucci ${ }^{1}$ and Karl Debray ${ }^{2}$ \\ 1. PSMS Laboratory, EA 7507, UFR STAPS, URCA, Reims 51100, France \\ 2. GReSPI MAN, EA 4694, URCA, Reims 51100, France
}

\begin{abstract}
The purpose was to create a stabilometric platform to analyze the rider's balance. After anatomical and saddle's mark study, four bones support points representing the rider's base were determined, that will allow the construction of our rider posture diagnostic aid platform. The sensors profile was realized and the stirrups dynamometers were calibrated through an extensometry study. To validate by comparison with a stabilometric platform (OIML 6000 sensors), one series of 28 observations under the same conditions were carried out (the two platforms adjusted one on the other), statistical analyses on the $\mathrm{X}$ and $\mathrm{Y}$ axis were performed with normality distribution test (S-W), $t$ test and non-parametric Wilcoxon-Mann-Whitney test ( $p$-value $>0.05$ ). To analyze our two methods of measuring the centre of pressure position, a Bland-Altman analysis has been plotted and the intra class correlation value computed. The Bland-Altman graph showed a small bias value $(-0.4 \pm 0.8 \mathrm{~mm})$ with acceptable limits of agreement for rider balance analyses. The results of the present study suggested that the new platform was accurate and reliable and could be used for further prospective studies in order to optimize the rider's posture and preserve the horse's health.
\end{abstract}

Key words: Low-cost, new device, rider balance, centre of pressure, stabilometric platform.

\section{Introduction}

The goal of this study is to create and scientifically validate a new equestrian device allowing the determination of a sitting equestrian postural norm in order to optimize the rider's balance and to preserve the horse's health. Subjective assessment of positional faults appears to be difficult. A panel of 5 experienced judges and trainers evaluated 60 horse and rider combinations according to the presence of 16 postural deviations. There was no statistical agreement between the assessments [1]. Ref. [2] has summarized the characteristics of equine gaits that affect the rider's position, movements and forces. A preliminary investigation of subjective assessment of rider technique and the detection of performance deficits suggests that it is difficult for trained equestrians to perform consistent evaluations. The use of objective research methods is necessary. Ref. [3] has shown that

Corresponding author: William Bertucci, full professor, research fields: sport biomechanics. the motion pattern of a well-ridden horse varies less than the motion pattern of an unridden horse. There are devices used in saddle fitting studies that can accurately determine the saddle position on the horse's back in order to obtain the perfect match between the saddle and the horse [4].

These mats are placed under the saddle, and we can computerize and deduce the rider's Centre of Pressure $(\mathrm{CoP})$. With the growing experience of the participant, an increase in pressure occurred on contact of the horses back as well as in the stability of the CoP, evaluated by an elastic pad, Novel Pliance System, 30 $\mathrm{Hz}, 224$ sensors [5]. Thus, the asymmetrical loading of the horse's back and different rider's positions on a standing horse were evaluated [6]. A study of postural and functional asymmetries of riders failed to find a discrepancy in leg lengths, with stratification by years of experience and competitive level [7, 8]. Ref. [9] quantified the force on the horse's back in sitting and rising trot by using kinematic data of the rider. The assessment of human pelvis kinematics in dressage 
riding has been done by an inertial sensor-based method. They showed that even between two riders of comparable riding level, significant differences in ROM (range of movement) of the pelvis can be found while riding the same horse [10]. Asymmetries in the rider's position or movements change the loading pattern on the horse's back and can alter the horse's locomotion [11, 12]. The proper rider's postural balance is both decisive for the good running of the horse, for the rider's and horse's performance [3, 13-15], as well as the defective rider posture, strength used or technical level [16, 17]. There are other attempts to objectify the rider's pressure on the saddle [18-20]. However, the results of these previous studies must be analyzed with caution because the devices are not statically validated (only one run and one horse) and no technical note about. There are equestrian simulators analyzing the rider's balance, but no technical note published [21, 22]. All these studies are based on the interpretation of the rider's support through the saddle transmission forces with elastic pad under the saddle; rider's kinematic by imaging and inertial units. Stirrup forces were measured in sitting and rising trot by Femke E. van Beek, de Cocq P., Timmerman M., Muller M., and concluded that a combination of stirrup and saddle force data can provide additional information on the total loading of the horse by a rider [23]. Ref. [24] concluded that a better understanding is required, he needs to know how to measure changes and different works patterns in moving horses, which are also affected both by the saddle and by the rider's ability to adjust their movements to accommodate the mechanical interaction with the horse. To allow the measurement of forces applied both on the saddle and on the stirrups, it is necessary to create and validate a new device.

\section{Materials and Methods}

\subsection{Saddle Platform}

A template was designed after saddle marks and anatomical measurements that allow the ergonomic construction of the new device named: "Aide au Diagnostic de la Posture du Cavalier" (Rider's Posture Diagnostic Aid) ADPC platform. The new ADPC will be created from anatomic and pelvimetric studies of the pelvis (data not shown, Business Secret Act KHP INT LTD registered to number 07469216). The saddle mark measurement's results and the pelvimetric study's analyses determined a four-bone support delimiting two specific diameters representing the rider's base. The pubis in front associated with the sacrum/coccyx couple behind determines the anteroposterior axis (Y) and laterally ischial tuberosities the mid-lateral axis (X). These four zones have been relevant to design a template (fig.1). In order to measure the load according to the different axes, we used four sensors Flexiforce FSR 400 [25]. These sensors were adapted to the saddle and resistant to friction. The acquisition chain included the analog domain with the sensors, the signal shaping circuit, the acquisition card which transforms the electrical signal into a digital signal and the digital domain with the computer processing unit, and the software $\mathrm{STO}^{\odot}$. The software has been created for the ADPC platform, sensor calibration, specifics rider's parameters, ludic and work screen (Fig.1). We calibrated several load sensors from a range of 0 to $190 \mathrm{~N}$. All these tests were made with an electrical resistance value of $3 \mathrm{k} \Omega$ because it was tested by the manufacturer (and the values were giving the most linear response according to the intensity of our loads). Sensors were positioned under a leather cover to protect them.

\subsection{Stirrup Sensor}

For the stirrup forces collected data, dynamometer Load Cell CZL301C [26] placed between the strap and the stirrup (Fig. 1) was chosen. Their response pattern was studied with a Gunt WP 120 (Hamburg) testing device at IUT with double check of the exerted force, a Wheatstone bridge torque sensor, range 0 to $1,000 \mathrm{~N}$ with safety up to $150 \%$ of the maximum 
tolerance value as shown in Fig. 4. A SEN-13879 amplifier to amplify the electrical signal was used with an Arduino Acquisition Card, the Arduino ${ }^{\odot}$ soft was modified $\mathrm{STO}^{\odot}$.

\subsection{Methods}

In the purpose of validating the new ADPC, this platform was superimposed on a stabilometric platform (Dune PL0002 with OIML 6000 sensors allowing an accuracy $\pm 0.1 \mathrm{~mm}$ ), centroid on centroid, mid lateral axis ADPC on mid lateral referent axis and anteroposterior axis ADPC on anteroposterior referent axis. This device provides the same biomechanical data (centre of pressure displacement measurements on the $\mathrm{X}$ and $\mathrm{Y}$ axis) as the new ADPC platform.

For the validation protocol, the force $(510 \mathrm{~N})(53$ years, $1.63 \mathrm{~m}$, mass $51 \mathrm{~kg}$, BMI $19.2 \mathrm{~kg} / \mathrm{m}^{2}$ ) shown in Fig. 1 was applied by one subject standing on the platforms (feet centred on the platform, tight feet, propped up by a posterior marker). One series of 28 observations under the same conditions were carried out. Electric zero was sought to stall ADPC on Dune. The subject climbed onto the platforms and looked at a target in front of his eyes at a distance of one meter. The both records were manually launched at the same time for duration of 25.6 seconds, half recording time calibrated by the reference platform. Data collection was carried out by both Equilibre ${ }^{\odot}$ and $\mathrm{STO}^{\odot}$ software.
The centre of pressure position was studied on two dimensions: $\mathrm{X}$ axis mid-lateral and $\mathrm{Y}$ axis anteroposterior.

A descriptive analysis of our variables was performed, using mean and standard deviation (SD), coefficient of variation $(\mathrm{CV})$, a normality distribution test by Shapiro-Wilk, a two-sided $t$ test for paired samples, and non-parametric Wilcoxon-Mann-Whitney test using ranks for independent sample. To analyze our two methods of measuring the same phenomenon (centre of pressure position) a correlation between the two devices was determined. The Bland-Altman analyses have been plotted and the intra class correlation value has been computed.

\section{Results}

\subsection{Saddle Sensors}

The smoothing law for the FSR sensor's behaviour used a logarithmic form: $y=0.8254 \ln (x)+1.2061$ with $R=0.996$. The trend's result of drift versus load was $0.8 \pm 0.2 \mathrm{bit} \cdot \mathrm{s}^{-1}$. The manufacturer's response time data is $2 \mathrm{~ms}^{-1}$.

\subsection{Stirrups Dynamometers}

The stirrups dynamometers study showed a monotone behaviour of 0 to $1,250 \mathrm{~N}(y=0.0959 x+$ 0.1371 and $r=1$ ).

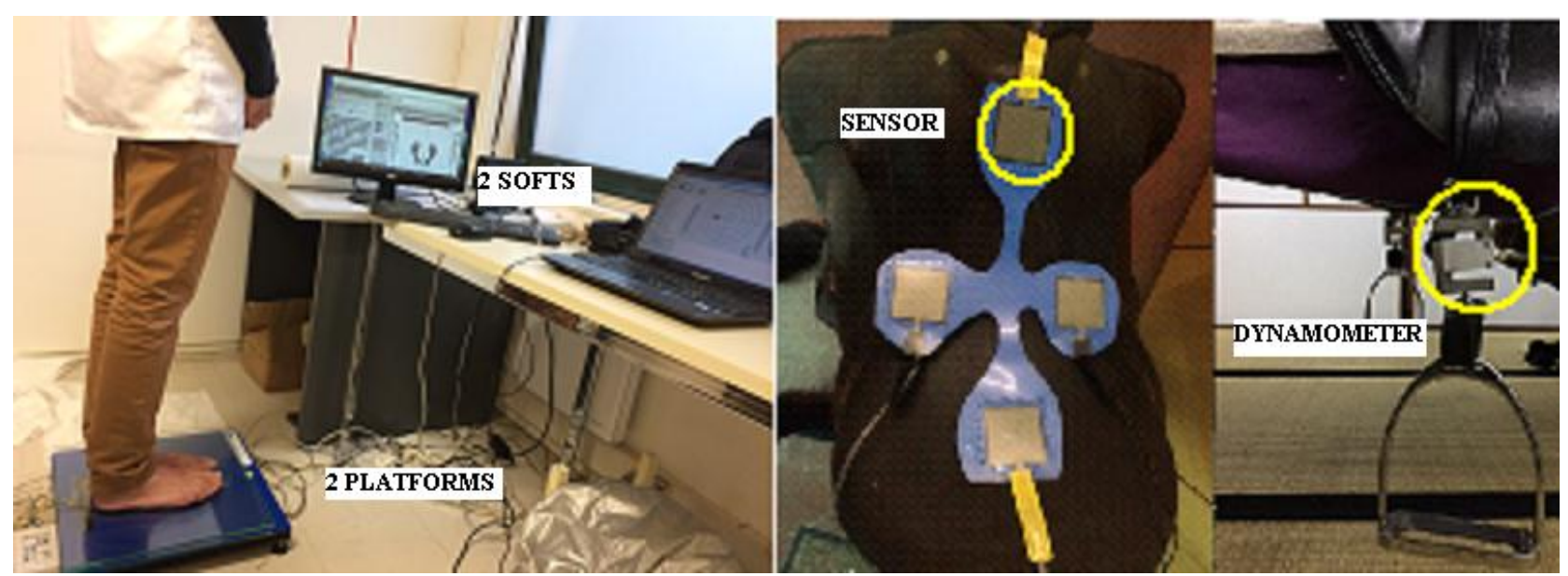

Fig. 1 Experiment of new horse saddle instrumented (ADPC), sensor, and dynamometer.

Left side, the subject centred on both platforms; in the centre the ADPC platform on the saddle; on the right, the stirrup sensors (dynamometer). 


\subsection{Descriptive Analysis}

The values $\left(\mathrm{X}_{\text {mean }}, \mathrm{Y}_{\text {mean }}\right)$ obtained by the two methods and described in Table 1 were not significantly different between the two devices for the two axes, but on the $\mathrm{X}$ axis, the CV ADPC device is bigger than the referent, which does not discredit the $\mathrm{X}_{\text {mean }}$ solidity (Table 1).

\subsection{Bland and Altman Analyses}

The Shapiro-Wilk test showed a normality distribution. The bilateral $t$ test showed that the two means are similar ( $p$-value $>0.05$ ). To confirm, the unilateral Wilcoxon-Mann-Whitney test showed that the two series of data were on the same distribution ( $p$-value > 0.05).

The Bland and Altman analyses shown in Fig. 2 reveal that the mid lateral axis (X), mean bias was -0.4 $\pm 2 \mathrm{~mm}$ with $95 \%$ limits of agreement of the bias from -4.3 to $3.6 \mathrm{~mm}$. The relationship (the Pearson
Correlation Coefficient between referent platform considered like reference and ADPC data on $\mathrm{X}$ axis) can be described by the following equation: $X$ $($ stabilometric platform $(\mathrm{mm}))=(0.3394 \times \mathrm{X}$ ADPC $)-$ $2.6544(r=0.46)$. For the $\mathrm{X}$ axis, our judgment of meaning is not asserted, but our judgment of interpretation is based on the Bland-Altman graph which shows a very small bias value. The Bland and Altman analysis for anteroposterior axis shows that $\mathrm{Y}_{\text {mean }}$ bias of $0.7 \pm 2.3 \mathrm{~mm}$ with a $95 \%$ limits of agreement of the bias from -3.8 to $5.3 \mathrm{~mm}$. The Pearson Correlation Coefficient showed that the relationship between referent platform and ADPC on $\mathrm{Y}$ axis can be described by the following equation: $\mathrm{Y}$ $($ referent platform $(\mathrm{mm}))=(1.0041 \times \mathrm{Y}$ ADPC $)+$ $0.7556(r=0.91)$.

Table 1 Comparison $(n=28)$ of the centre of pressure on $X$ and $Y$ axis between the referent device and the new ADPC.

\begin{tabular}{llllllll}
\hline & Platform & $\begin{array}{l}\text { mean } \\
(\mathrm{mm})\end{array}$ & $\begin{array}{l}\text { SD } \\
(\mathrm{mm})\end{array}$ & $\begin{array}{l}\mathrm{CV} \\
(\%)\end{array}$ & $\begin{array}{l}\text { Bias } \\
(\mathrm{mm})\end{array}$ & $\begin{array}{l}\text { Confidence interval } \\
(\mathrm{mm})\end{array}$ & $\begin{array}{l}\text { Limits of agreement } \\
(\mathrm{mm})\end{array}$ \\
\hline X axis & Ref & -3.8 & 1.6 & 42 & -0.4 & $-0.4 \pm 0.8$ & $-0.4 \pm 3.9$ \\
& ADPC & -3.4 & 2.2 & 108 & & & $0.7 \pm 4.5$ \\
\hline Y axis & Ref & -10.6 & 5.7 & 38 & 0.7 & $0.7 \pm 0.90$ & \\
& ADPC & -11.3 & 5.2 & 28 & & & \\
\hline
\end{tabular}

Ref referents platform. ADPC is low-coast platform. Bias is the average of the differences between the two platforms; the confidence interval is used to quantify the confidence we can have in our bias estimate. The interpretation of the limits of agreement is done in relation to the research context.

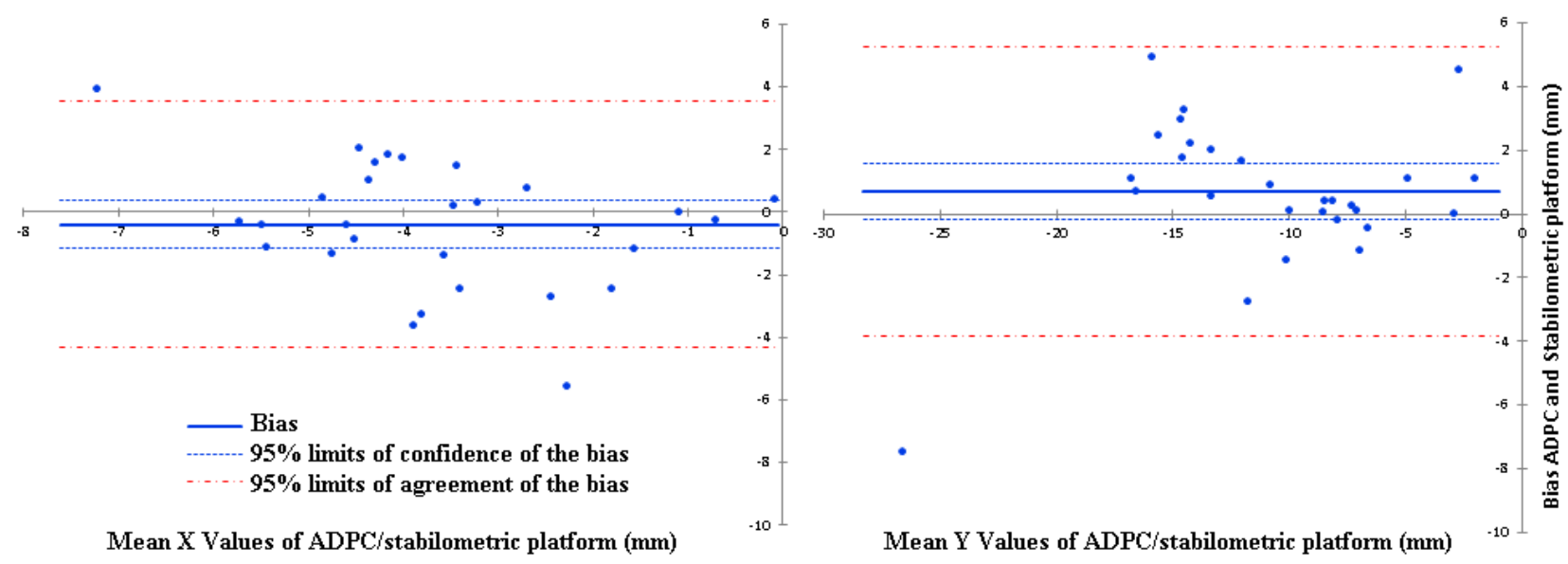

Fig. 2 Bland Altman graphics for mediolateral $(\mathrm{X})$ axis and anteroposterior (Y) axis. 
In blue line the bias, in dashed blue the confidence interval of the $95 \%$ bias and in red dashed the $95 \%$ confidence interval of the differences. In the left side, $\mathrm{X}$ axis (mid-lateral) analyse and in the right part for the $\mathrm{Y}$ axis (anteroposterior).

\section{Discussions}

The results of a study conducted with 125 subjects showed that the width of the ischial tuberosities supports of 5 subjects was out of the platform (too narrow and too wide), and that the length corresponded to the entire population studied (age 34 \pm 15 years, size $168.5 \pm 8.7 \mathrm{~cm}$, weight $66.7 \pm 12.8 \mathrm{~kg}$, BMI $23.4 \pm 3.8 \mathrm{~kg} / \mathrm{m}^{2}$, riders an no riders). The ADPC platform proportions (length and width) correspond to $96 \%$ of our population. The result allowed the choice of FSR sensors with identical response patterns to pair them. The new device is suitable for the majority of riders. The sensors protected proved effective and comfortable for the users. Pliance Novel $\odot$ has created a unique material for the objective analysis of the distribution of pressure exerted by the rider through the saddle on the horse's back [18]. To our knowledge, the presence of a pressure sensor mat placed on the saddle appears for the only time in this study, unfortunately no technical information has been published on the subject.

For the stirrups dynamometers showed in Fig. 1, we observe an inflection of the curves beyond 1,250 $\mathrm{N}$ of stress. We know that their range of use is from 0 to $1,000 \mathrm{~N}$, we have a security of $25 \%$, giving us a range of use from 0 to $1,250 \mathrm{~N}$. We are certain to have sensors that will cash the mass of riders when standing on the stirrups, such as CSO riders, or during a trot phase removed. The pic of raw stirrup force measured at rising trot does not exceed $900 \mathrm{~N}$ with 23 riders (mean age $18.0 \pm 1.7$ years; height $1.70 \pm 0.01 \mathrm{~m}$; mass $61 \pm 1 \mathrm{~kg}$ ) [23].

The results suggest that there was no difference of the centre of pressure in $\mathrm{X}$ and $\mathrm{Y}$ axis for stabilometric platform taken in reference and ADPC devices (Table 1). The Bland-Altman graph showed a very small bias between the two devices (Fig. 2). The zero baselines were systematically included in the
95\% confidence intervals. All the variables moved in the same direction and with similar amplitude. The difference between the reference device and the new ADPC device can be considered acceptable for the measurement of rider's balance. Given the context of use, we consider these values to be consistent. The results suggested that the new platform ADPC was accurate and reliable. As the $\mathrm{CV}$ score on the $\mathrm{x}$-axis is smaller for referent platform, the $\mathrm{x}$-axis correlation analysis approves this difference with $r=0.46$. A second study with a series of 16 observations (55 years old, mass $72 \mathrm{~kg}$, size $1.70 \mathrm{~m}$, BMI $24.91 \mathrm{~kg} / \mathrm{m}^{2}$ ), is carried out under the same experimental conditions, confirmed the results (bias $-0.2 \pm 2 \mathrm{~mm}$ and $-1.1 \pm 3.7$ $\mathrm{mm}$, respectively $\mathrm{X}$ axes and $\mathrm{Y}$ axes). Both studies showed a negative bias, which explained that ADPC returns data that are inferior to the referent platform. This second study did not confirm the CV difference on the $\mathrm{X}$ axes (76 and 96\%), $\mathrm{Y}$ axes (89 and 60\%), respectively referent/new platform). Even though the CVs seem high, this is due to the near-zero value of the mean measured, so the CV flies off. They are still the same size.

Fig. 3 shows the displacement of the centre of pressure during an experimental sitting trot session. In this graph, all the points are positive on the anteroposterior axis, then the rider is in support forward, on the mid-lateral axis the majority points are positive, then the rider is in support on the right. Fig. 4, shows a more important support on the left stirrup (red line). The posture analysis reveals that the rider has an asymmetrical dynamic balance on the saddle.

\subsection{Limits}

Saddle sensors are passive with a lifetime $>$ several millions of requests. In view of the extreme conditions of use, we do not know their duration in time.

It is likely that the shift from the manual start of the 
data record changes the exact data correlation and influences our results. The relative error computed is $1.95 \%$ for half a second of discordance. In this search context, even with $1.95 \%$ of relative error, the results remain concordant.

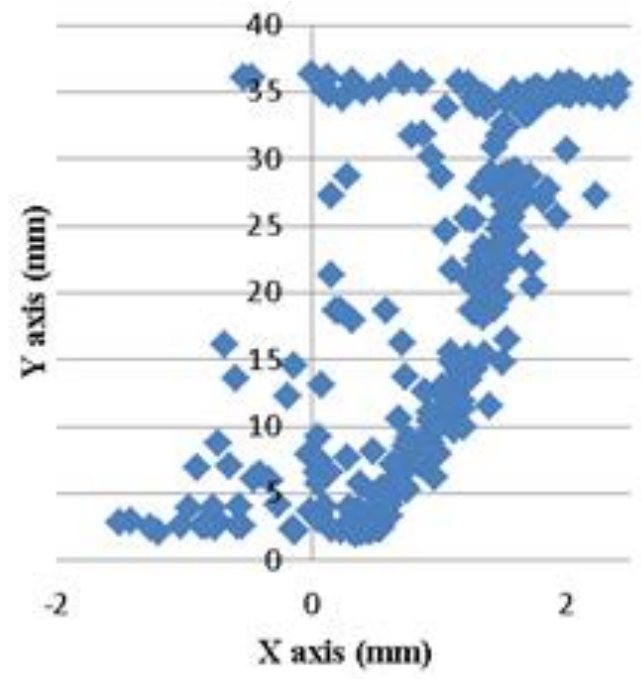

Fig. 3 Example of Saddle centre of pressure (on $\mathrm{X}$ and $\mathrm{Y}$ axis).

Example of displacement of the centre of pressure $(\mathrm{mm})$ on the saddle, during a test. Positive displacement on $y$-axis translates forward motion, positive displacement on $\mathrm{x}$-axis translates rightward shift.

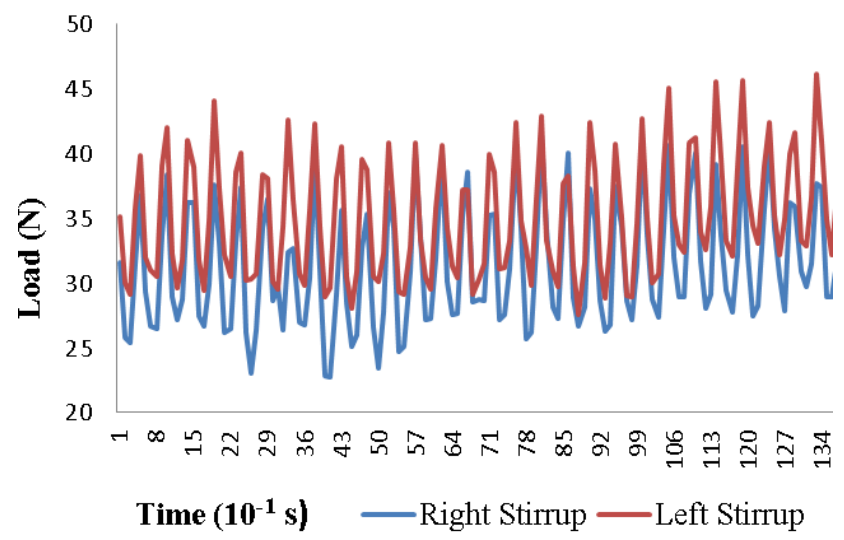

Fig. 4 Example of stirrups load measurements with ADPC device for one rider $(510 \mathrm{~N})$ on horse simulator trotting $1.4 \mathrm{~Hz}$. Sample graph of the load $(\mathrm{N})$ applied to the stirrups/beats during a test, the blue line corresponds to the force exerted on the right stirrup, the red one to that exerted on the left stirrup.

We are critical of the risk of over/under-estimating the vertical component or the reality of the total pressure exerted on the saddle, for several reasons: (i) the force component is not systematically normal to the surface of the sensor as shown in Fig. 5, (ii) the shear forces are not known and (iii) the dispersion of forces related to the thighs support on the sides of the saddle is not recorded, illustrated in Fig. 6.

Mean normalized total force measured on a saddle-mounted horse was lower than expected, observed in an analysis with Pliance Novel mat (60 $\mathrm{Hz}$ ) positioned under the saddle, for the comparison of riding with and without saddle [27]. This is confirmed by de Cocq et al. [9] and Femke et al. who ask the question if the whole vertical force is displaced to the stirrups during the standing phase or if the rider also uses the friction on other surfaces of contact with the horse. The proportion of forces exerted by the thighs 
support of the riders on the saddle side (quarters), Fig. 6 , and the proportion of the forces exerted on the stirrups, allow (i) a relative safety as for the forced use of our sensors, and

(ii) calculation error on the

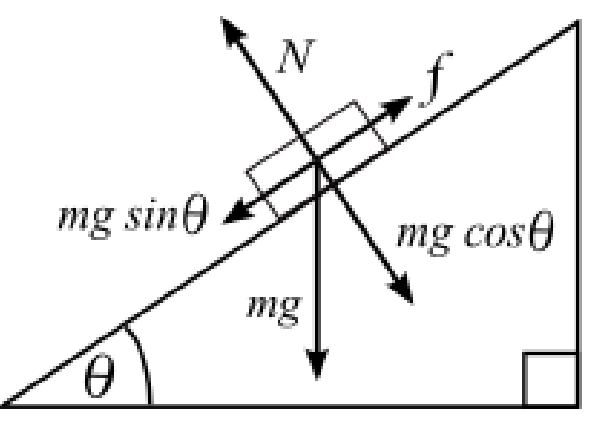

Fig. 5 Analysis of the forces decomposition exerted on the saddle sensor. $\mathrm{m}=$ mass of the subject, $\mathrm{g}=$ acceleration, $\Theta=$ measured inclination angle/horizontal.

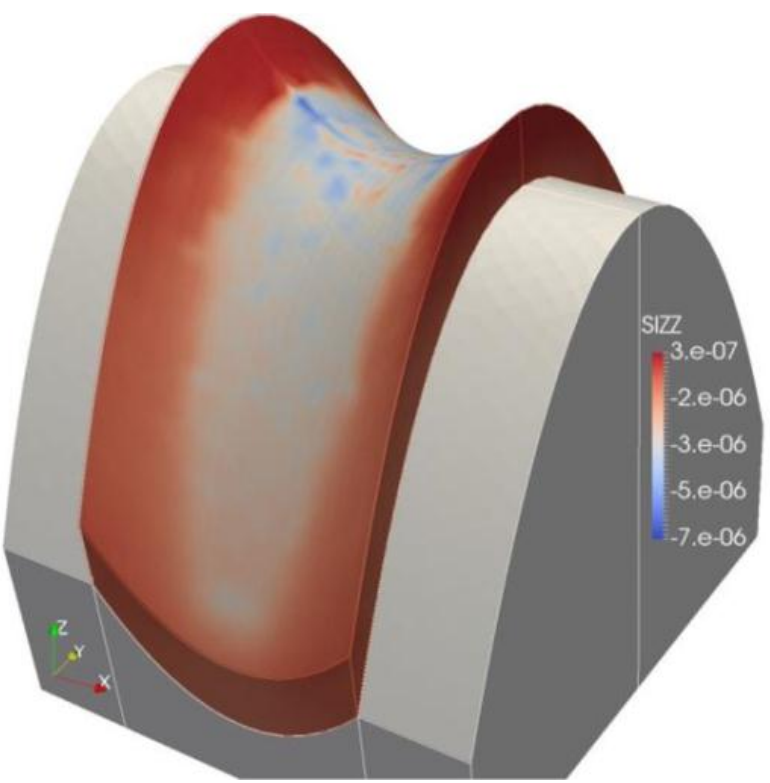

Fig. 6 Iso-values illustration of the pressure on the saddle with friction.

Preliminary SIZZ representation of the most stressed zones present on the static vertical axis, at the interface of the rider and the saddle. The side faces of the saddle participate in the dispersion of the pressures exerted by the rider.

distribution of the riders mass.

In addition, the shape of the horse, and ispo-facto the shape of the saddle, affect the application incidence angle of the force applied on the sensor, shown in Fig. 5. If we knew the incidence angle $\theta$, we could deduce (i) the normal force exerted by bone support $(\mathrm{mg} \cdot \cos \theta)$ on the surface of the sensor and (ii) the sliding force $(\mathrm{mg} \cdot \sin \theta)$. We are able to determine the CoP displacement, but we cannot exploit these data to analyze the total force exerted on the saddle.

\subsection{Contributions}

The CoP of our study is characterized by variables $\mathrm{X}_{\text {mean }}, \mathrm{Y}_{\text {mean }}$ (and their respective standard deviation). At the moment, the equestrian literature is limited to the use of the variables (range of $\mathrm{X}$ and $\mathrm{Y}$ ) that characterize the $\mathrm{CoP}$. The position of $\mathrm{CoP}$ is calculated on the basis of the amplitude and distribution of forces applied to a pressure sensor mat (under a saddle) and allows the calculation of the amplitude and speed of $\mathrm{CoP}$ displacement. These parameters provide a basis for understanding the implications of the variations that can be created during riding on the rider's postural control [5, 28-31]. 
Each element in interface between the rider and the horse (the saddle, the stirrups, the mat) must be analyzed separately in order to know their isolated effect on the variable CoP [6]. This is what our new device does by differentiating the rider's support between the saddle and stirrups. We highlight the need for a common $\mathrm{CoP}$ analysis methodology in order to pool or compare our results.

Our originality is to have created an independent device, independent from the saddle and independent of the stirrup. It is an easy-to-replace element in case of failure, for a low-cost. This will allow a wide dissemination to get a lot of measurements. The new ADPC device (saddle and stirrups pressure) will be able to help the coaches and the researchers to study the rider's possible balance disorders to preserve the horse's health.

\section{Conclusion}

The purpose of this study was to create and validate a new device to allow analysis of the proper rider's balance. To the best our knowledge, the $\mathrm{ADPC}^{\odot}$ device (Fig. 1) is the only one saddle device scientifically tested and validated to explore the rider's balance.

Our perspective is (i) to help advance theoretical and practical understanding of the control and organization of rider movement, (ii) and study physical disorders such as scoliosis, osteoarthritis of coxo-femoral joint, sprained knee, orthodontics braces, and whiplash injury syndrome to determine influences on the rider's balance. We created specific posture exercise placements with a referent horse simulator equipped with the device. To date we are the only ones to offer this type of equipment in such configurations of use (discriminating, fun and low-cost).

\section{References}

[1] Blokhuis, A. Z., Aronsson, A., Hartmann, E., Van Reenen, C. G., and Keeling, L. 2014. "Assessing the Rider's Seat and Horse's Behavior: Difficulties and
Perspectives." Journal of Applied Animal Welfare Science 11: 191-203.

[2] Clayton, H. M., and Hobbs, S -J. 2017. "The Role of Biomechanical Analysis of Horse and Rider in Equitation Science." Applied Animal Behaviour Science 190: 123-13.

[3] Peham, C., Licka, T., Schobesberger, H., and Meschan, E. 2004. "Influence of the Rider on the Variability of the Equine Gait." Human Movment Science 23 (5): 663-71.

[4] De Cocq, P., van Weeren, P. R., and Back, W. 2005. "Saddle Pressure Measuring: Validity, Reliability and Power to Discriminate between Different Saddle-Fits." The Veterinary Journal 172 (2): 265-73.

[5] Janura, M., Peham, C., Dvorakova, T., and Elfmark, M. 2009. "An Assessment of the Pressure Distribution Exerted." Human Movement Science 28: 387-93.

[6] De Cocq, P., Clayton, H., Terada, K., Muller, M., and Van Leeuwen, J. 2009. "Usability of Normal Force Distribution Measurements to Evaluate Asymmetrical Loading of the Back of the Horse and Different Rider Positions on a Standing Horse." The Veterinary Journal 181: 266-73.

[7] Hobbs, S. J., Baxter, J., Broom, L., Dagg, L.-A., Sinclair, J. K., and Clayton, H. M. 2014. "Posture, Flexibility and Grip Strength in Horse Riders." Journal of Human Kinetic 42: 113-25.

[8] Hobbs, S. J., Richards, J., and Clayton, H. M. 2014. "The Effect of Centre of Mass Locationon Sagittal Plane Moments around the Centre of Mass in Trotting Horses." Journal of Biomechanics 47: 1278-86.

[9] De Cocq, P., Duncker, A., Clayton, H., Bobbert, M., Muller, M., and van Leeuwen, J. 2010. "Vertical Forces on the Horse's Back in Sitting and Rising Trot." Journal of Biomechanics 43: 627-31.

[10] Münz, A., Eckardt, F., Heipertz-Hengst, C., Peham, C., and Witte, K. 2013. "A Preliminary Study of an Inertial Sensor-Based Method for the Assessment of Human Pelvis Kinematics in Dressage Riding." The Journal of Equine Veterinary Science 33 (11): 950-5.

[11] Licka, T., Kapaun, M., and Peham, C. 2004. "Influence of Rider on Lameness in Trotting Horses." Equine Veterinary Journal 36: 734-6.

[12] Nevison, C. M., and Timmis, M. S. 2013. "The Effect of Physiotherapy Intervention to Thepelvic Region of Experienced Riders on Seated Postural Stability and Thesymmetry of Pressure Distribution to the Saddle: A Preliminary Study." Journal of Veterinary Behavior 8: 261-4.

[13] Lagarde, J., Kelso, J., Peham, C., and Licka, T. 2005. "Coordination Dynamics of the Horse-Rider System." Journal of Motor Behavior 37 (6): 418-24.

[14] Schölhorn, W., Peham, C., Licka, T., and Scheidl, M. 
2006. "A Pattern Cecognition Approach for the Quantification of Horse and Rider Interactions." Equine Veterinary Journal 36: 400-5.

[15] Nicol, C., Viry, S., and Laurent, M. 2012. "Effect of Expertise on the Biomechanics of the Rider/Horse Pair in Endurance Competitions: Pilot Study." 38ème journée de la Recherche Equine. Ed le pin au haras IFCE (March): 129-38. (in French)

[16] Symes, D., and Ellis, R. 2009. "A Preliminary Study into Rider Asymmetry within Equitation." Veterinary Journal 181: 34-7.

[17] Alexander, J., Hobbs, S.J., May, K., Northrop, A., Brigden, C., and Selfe, J. 2015. "Posturalcharacteristics of Female Dressage Riders Using 3D Motion Analysis and Theeffects of an Athletic Taping Technique: A Randomised Control trial." Physical Therapy in Sport 16: 154-61.

[18] Nicol, G., Arnold, G. P., Wang, W., and Abboud, R. J. 2014. "Dynamic Pressure Effect on Horse Rider during Riding." Sports Engineering 17 (3): 143-50.

[19] Cressent, M. 2012. "Measurement at the Service of Performance." Ed le pin au haras IFCE 79: 51. (in french)

[20] Biau, S., and Debril, J.-F. 2017. "Description of Aids in Trotting and Galloping in a Straight Line." 43ème journée de la recherche equine, Ed le pin au haras IFCE (March): 109-16. (in French)

[21] Galloux, P., Jinenez, M., Richard, N., Dronka, T., Leard, M., Jouffroy, J. L., and Chollet, A. 1995. "Analysis of the Saddle Movement at Three Speeds by an Accelerometric Technique for the Simulation of a Platform with Six Degrees of Freedom." Equathlon 7 (28): 22-7. (in French)

[22] Mager-Maury, S., Biau, S., and Deslandes, S. 2012. "Use of Motion Trackers for Equine Locomotion Analysis to Implement a Horse Simulator." Computer Methods in Biomechanics and Biomedical Engineering 15: 127-8.

[23] van Beek, F. E., de Cocq, P., Timmerman, M., and
Muller, M. 2012. "Stirrup Forces during Horse Riding: A Comparison between Sitting and Rising Trot." Veterinary Journal 193: 193-8.

[24] Greve, L., and Dyson, S. 2013. "The Horse-Saddle-Rider Interaction.” The Veterinary Journal 195: 275-81.

[25] Interlink Electronic, DataSheet-FSR400- 94-00010 Rev., Accessed April 03, 2018. https://cdn.sparkfun.com/datasheets/Sensors/ForceFlex/2 010-10-26-DataSheet-FSR400-Layout2.pdf.

[26] S type Load Cell (0-100Kg)-CZL301C, specifications. $\begin{array}{lll}\text { Accessed } & \text { September } & 12,\end{array}$ www.phidgets.com/?tier $=3 \&$ catid $=9 \&$ pcid $=7 \&$ prodid $=229$.

[27] Clayton, H., Belock, B., and Kaiser, L. 2013. "Forces and Pressures on the Horse's Back during Bareback Riding." The Veterinary Journal 195 (1): 48-52.

[28] Jeffcott, L., Holmes, M., and Townsend, H. 1999. "Validity of Saddle Pressure Measurements Using Force-Sensing Array Technology Preliminary Studies." The Veterinary Journal 158 (2): 113-9.

[29] Clayton, H., Kaiser, L., de Pue, B., and Kaiser, L. 2011. "Center of Pressure Movement during Aquine assisted Activities." American Journal of Occupational Therapy 65: 211-6.

[30] Ramseier, L., Waldern, N., Wiestner, T., von Peinen, K., and Weishaupt, M. 2013. "Saddle Pressure Distributions of Three Saddles Used for Icelandic Horses and Their Effects on Ground Reaction Forces, Limb Movements and Rider Positions at Walk and Töld." The Veterinary Journal 198: e81-7.

[31] Flores, F., Dagnese, F., Mota, C. B., and Copetti, F. 2015. "Parameters of the Center of Pressure Displacement on the Saddle during Hippotherapy on Different Surfaces." Brazilian Journal of Physical Therapy 19 (3): 211-7. 